\title{
Província das Alagoas, Brasil: a presença de alunos órfãos, pretos e pardos nas aulas avulsas de ensino secundário (1844-1847)
}

Province of Alagoas, Brazil: the presence of black, browns and orphans students in the sparse classes of secondary school (1844 - 1847)

Provincia de las Alagoas, Brasil: la presencia de alumnos huérfanos, negros y pardos en las clases singulares de enseñanza secundaria (1844-1847)

Ivanildo Gomes dos Santos

Faculdade Raimundo Marinho (Brasil)

https://orcid.org/0000-0002-8667-1854

http://lattes.cnpq.br/8645485364498015

ivanildoeduc@hotmail.com

Mauricéia Ananias

Universidade Federal da Paraíba (Brasil)

https://orcid.org/0000-0002-8594-8436

http://lattes.cnpq.br/7637107120810469

mauriceia.ananias@gmail.com

\section{Resumo}

O texto objetiva revelar particularidades históricas da Província das Alagoas no que diz respeito à presença de alunos órfãos, pretos e pardos nas chamadas aulas avulsas do ensino secundário, ainda na primeira metade do século XIX. A pesquisa consistiu, sobretudo, na localização, transcrição e análise de mapas escolares das aulas de Gramática Latina tanto da capital quanto do interior da Província, produzidos entre 1844 e 1847, pelos professores da época. Os referidos mapas encontram-se acondicionados no Arquivo Público de Alagoas, Brasil. Utilizando os aportes teórico-metodológicos de Fonseca (2007), Veiga (2008) e Cruz (2009), buscamos redimensionar a situação e ação social dos negros para além da escravização e marginalização, tendo em vista que também eles estiveram inseridos no processo de escolarização e civilização.

Palavras-chave: Aulas avulsas. Ensino secundário. Alunos órfãos, pretos e pardos. 


\begin{abstract}
The text is intend to reveal historical particularities of Province of Alagoas with regard to the presence of orphans, blacks and browns in the so-called sparse classes of the secondary education, yet in the first half of the nineteenth century. The research consisted mainly in locating, transcribing and analyzing school maps Latin Grammar classes both in the capital and in the interior of the Province, produced between 1844 and 1847 by the teachers of the time. The said maps are shelved in the Public Archive of Alagoas, Brazil. Using the theoretical-methodological contributions of Fonseca (2007), Veiga (2008) and Cruz (2009), we sought to reshape the situation and social action of blacks beyond enslavement and marginalization, considering that they too they too were inserted in the schooling process and civilization.
\end{abstract}

Keywords: Sparse classes; Secondary school; Orphaned students, black and brown.

\title{
RESUMEN
}

El texto tiene por objeto revelar particularidades históricas de la Provincia de las Alagoas en lo que se refiere a la presencia de alumnos huérfanos, negros y pardos en las llamadas clases singulares de la enseñanza secundaria, aún en la primera mitad del siglo XIX. La investigación consistió, sobre todo, en la localización, transcripción y análisis de mapas escolares de las clases de Gramática Latina tanto de la capital cuánto del interior de la Provincia, producidos entre 1844 y 1847, por los profesores de la época. Los mencionados mapas se encuentran envasados en el Archivo Público de Alagoas, Brasil. Utilizando los aportes teórico-metodológicos de Fonseca (2007), Veiga (2008) e y Cruz (2009), buscamos redimensionar la situación y acción social de los negros además de la esclavización y marginalización, teniendo en vista que ellos también han estado introducidos en el proceso de escolarización y civilización.

Palabras-clave: Clases singulares. Enseñanza secundaria. Alumnos huérfanos, negros y pardos. 


\section{Introdução}

No Brasil, o ensino secundário foi introduzido pelos jesuítas, embora outras ordens religiosas como os carmelitas, os franciscanos e os beneditinos também tenham se dedicado a esse nível de ensino. Os colégios da Companhia de Jesus, ancorados na Ratio Studiorum, introduziram uma cultura letrada num ambiente ágrafo, em que era notável a diferenciação entre o ensino de humanidades dado aos filhos das elites e um ensino mais voltado à catequese destinado aos grupos nativos. Com a expulsão dos jesuítas pela política pombalina, em 1759, o ensino secundário brasileiro configurou-se em aulas avulsas em todas as capitanias, mantendo, no entanto, a mesma divisão entre elites e pobres. Os liceus fundados no período imperial seguiram a mesma caracterização e tinham, sobretudo, a função social de preparar para as faculdades aqueles que viriam formar a elite político-administrativa das províncias e do Estado nacional brasileiro que se desenhava.

Diante dessa constatação, a matrícula e frequência de alunos órfãos, pretos e pardos nas aulas avulsas de Gramática Latina, nas Alagoas, possibilitam-nos problematizar um dos paradigmas dos estudos e pesquisas no âmbito da historiografia da educação a respeito do ensino secundário brasileiro no século XIX. Esse pressuposto, seguido pela maioria dos estudiosos da área, parte da referência inicial de que aquele modelo de ensino era destinado somente às elites e, consequentemente, para alunos brancos, não sendo admitida a frequência de alunos pretos e pardos.

Recorrendo às evidencias empíricas apresentadas ao longo do texto, configuramos uma hipótese de trabalho no sentido de confirmar que se tratava de alunos das camadas menos afortunadas, não aqueles para quem o ensino secundário foi concebido, ainda que haja a possibilidade de que pertencessem a grupos sociais mais abastados. Segundo Cruz (2009), embora o critério da cor fosse a principal forma de distinguir os grupos sociais, nem sempre era possível saber "[...] quem de fato se encontrava na condição de cativo, quando se tratava de um africano ladino ou um negro crioulo, principalmente, nas regiões urbanas, onde as atividades econômicas executadas permitiam maior autonomia [...]" (CRUZ, 2009, p. 113). Além disso, a orfandade, por si só, não indicava condição de pobreza, tendo em vista que os filhos das elites também ficavam órfãos.

O recorte temporal priorizado, dos anos de 1844 a 1847, justifica-se pela própria existência e localização dos documentos analisados que estão acondicionados no Arquivo Público de Alagoas, Brasil. As fontes principais são os mapas escolares manuscritos por professores da época ${ }^{1}$. O primeiro, do professor padre Francisco de Assis Ribeiro, da aula de Latinidade de Maceió, datado do ano de 1844; o segundo, do professor Leopoldino Antonio Fonseca, da aula de Latim da Vila de Atalaia, remonta ao ano de 1847; e o terceiro, do professor padre Antonio Craveiro de Barros Leite, da aula de Latinidade da Cidade de Penedo, também de 1847.

O aporte teórico-metodológico utilizado baseia-se em Fonseca (2007), Veiga (2008) e Cruz (2009) buscando redimensionar a situação e ação social dos negros para além da escravização e marginalização, tendo em vista que também eles estiveram inseridos no

\footnotetext{
${ }^{1}$ Mapas escolares eram documentos elaborados pelos professores da educação primária e secundária, que deveriam ser entregues em tempo hábil aos Inspetores. De função burocrática, eles serviam, sobretudo, para atestar a matrícula e frequência dos alunos, bem como, para o pagamento do ordenado dos professores. Assim, constituíam-se em instrumentos de controle do trabalho docente. Além disso, permitia o acesso a uma série de informações dos alunos, a exemplo dos nomes, filiação, naturalidade, conduta, cor da pele, adiantamento.
} 
processo de escolarização e civilização. Assim, pretendemos contribuir com a discussão pouco explorada acerca da presença de grupos sociais menos abastados, sobretudo, negros e pardos, no ensino secundário no século XIX. ${ }^{2}$

Importante salientar que, conforme o Mapa da população da Província das Alagoas, de $1849^{3}$, de um total de 207766 "almas", cerca de $70 \%$ eram negros ou pardos, sendo que $72 \%$ eram escravizados e apenas $28 \%$ livres ou libertos. Essa extensa parte da população das Alagoas não tinha acesso à escolarização, assim, chamamos atenção para o fato de que esses negros e pardos admitidos ao ensino secundário, ainda que em pequeno número, entraram em contato com a cultura letrada, o que lhes possibilitou a aquisição do domínio dos códigos de conduta das pessoas livres e consideradas, por parte da sociedade, como civilizadas. No arranjo social da época, a presença desses "homens de cor" na instrução secundária, além de testemunhar a circulação de pretos e pardos no interior da sociedade alagoana, garantiu-lhes condições de exercer os mais diversos papéis na Província e fora dela.

O texto foi dividido, para além da introdução, em duas partes: no primeiro momento, analisamos a presença de um aluno órfão, Justiniano Honorato de Almeida, na aula de Gramática Latina de Maceió, capital da Província, no ano de 1844, bem como a sua trajetória social e de sua família. Na sequência, tratamos da presença de alunos pretos e pardos nas cadeiras de Gramática Latina das vilas de Atalaia e Penedo, no interior da Província, ambos de 1847. Por fim, apresentamos as considerações finais.

\section{O aluno órfão da aula de Gramática Latina de Maceió}

O primeiro mapa analisado foi o da cadeira de Latim de Maceió, pertencente ao professor padre Francisco de Assis Ribeiro. Em manuscrito datado de 15 de março de 1844, Ribeiro atesta ter matriculado em sua aula 23 alunos. A listagem dos alunos obedecia a uma ordem hierarquizada de saberes, que ia dos conhecimentos mais simples, como adjetivos, aos mais complexos, a exemplo do estudo das obras de Salustio e Virgílio, sendo os mais adiantados considerados Provectos ${ }^{4}$. Dentre estes estavam: José Francisco Soares, Delfino José Oliveira e José de Souza Barboza. Sete alunos estavam estudando Salustio e Virgílio, quatro estudando Cornélio e fábulas, e os demais tinham adiantamento em sintaxe, nominativos, linguagem e adjetivos. Todos contavam com boa conduta e as idades variavam entre 12 e 21 anos. Na coluna destinada à paternidade aparece o nome de algumas mulheres, como Felicidade Perpectua, mãe de Aprigio Justiniano de Goes, D. Anna Joaquim da Costa, mãe dos alunos Ignacio Joaquim da Costa e João Luiz de Araujo, e Maria Margarida de [Ilegível], mãe de Custodio Francisco de Mello.

Um dos alunos teve o quadro paternidade preenchido como órfão. Tratava-se de Justiniano Honorato de Almeida, natural de Penedo e com 15 anos de idade. D'Almeida, como os demais alunos, tinha boa conduta e encontrava-se na lição de sintaxe.

Outras fontes nos forneceram indícios da trajetória profissional e familiar de Justiniano Honorato. Uma carta, datada de 25 de setembro 1888, enviada ao conselheiro do

\footnotetext{
${ }^{2}$ Importante destacar que a documentação analisada (Mapas escolares) apresenta as terminologias preto e pardo, conforme apresentamos no título do artigo. Entretanto, em algumas partes do texto fizemos a escolha pelo uso do termo negro, pois é uma categoria que cada vez mais ganha reconhecimento e significados nos estudos que abordam os extratos preto, pardo, crioulo e cabra na sociedade brasileira. Para melhor entendimento dessa terminologia, consultar Fonseca (2007).

${ }^{3}$ Mappa resumido da população da Provincia das Alagoas. Fonte: http://brazil.crl.edu/bsd/bsd/15/000038.html. Acesso em 12 mar. 2017.

${ }^{4}$ Os mapas não indicam quais obras desses autores eram estudadas. Possivelmente tratavam-se de Guerra Catilinaria, de Salústio, e Éclogas e Eneida, de Virgílio, pois eram frequentemente utilizadas nas aulas secundárias de latim no século XIX, conforme apontam pesquisas de Arriada (2007) e Ferronato (2012).

${ }^{5}$ Arquivo Público de Alagoas. Mapas escolares, 1844. Cx. 0061.
} 
Império, João Alfredo Correia de Oliveira, o egresso da aula de Gramática Latina pleiteou promoção da função que exercia no serviço público. Na mensagem, D’Almeida afirma que foi durante mais de 40 anos funcionário público da Fazenda da Província das Alagoas. Assegura que por essa repartição exerceu diversos cargos como: guarda simples de primeira classe; oficial de descarga; segundo escriturário na Alfândega de Penedo, quando instalada em 1868; e como Segundo Escriturário da tesouraria, cargo que ocupava quando fez uma petição ao conselheiro. Na carta solicitando a ascensão, d'Almeida destaca que também trabalhou na comissão especial para construção da estrada de ferro de Paulo Afonso, em 1883. E como razões que corroboram o pedido apresentou o seguinte:

O mesmo abaixo assignado é casado e tem a seu cargo numerosa família, cujos filhos precisam actualmente de instrucção, o mais seguro penhor que podem os paes legar a seus filhos:

Conta mais de quarenta (40) annos de serviços consecutivos prestados à Fasenda geral na alfândega de Maceió [...].

Durante longo periodo de servidor do Estado só gosou de quinze dias de licença sem vencimentos, dentro dos quais veio a capital a fim de acompanhar a sua família, visto ter sido prolongada sua commissão n'aquella alfandega ${ }^{6}$.

Conforme já afirmamos, o fato de ter sido órfão, por si mesmo, não indicaria a situação de pobreza do aluno, uma vez que os filhos de pessoas ricas também poderiam ficar órfãos. Entretanto, o acompanhamento dos indícios deixados pelo sujeito reforça nossa presunção que no caso em tela tratava-se de um aluno pobre. Primeiramente, por utilizar a justificativa de uma família numerosa que pareceu algo plausível da parte do requerente para pleitear condições financeiras de instruir toda a sua prole. E, sobretudo, a associação e utilização dos serviços da Sociedade de Instrução e Amparo dos Caixeiros (1882-1884) ${ }^{7}$ por um de seus filhos. A Sociedade era constituída por artesãos, operários e empregados das casas comerciais de Maceió e dentre outras atividades oferecia aulas noturnas voltadas à formação mercantil. Vale lembrar que, à época, o estudo em aulas noturnas poderia indicar situação de pobreza ou de sociabilidade entre os trabalhadores para formação de seus pares, ou de pessoas próximas a ele.

Conforme informações registradas nos assentos de batismo da Catedral Nossa Senhora dos Prazeres, em Maceió, casado com Guilhermina Lima de Almeida, Justiniano Honorato de Almeida teve pelo menos sete filhos: João Almeida (João Luiz Honorato de Almeida), batizado em 16 de junho de 1859; Graciliano de Almeida (Graciliano de Almeida Xexeo), que nasceu em 12 de agosto de 1862 e foi batizado em 14 dezembro do mesmo ano; Octaviano de Almeida, batizado em 05 de março de 1864; Octavia de Almeida, batizada em 05 de março de 1864; Cecilia de Almeida, nascida em 02 de junho de 1871 e batizada em 10 de fevereiro de 1877; Ritta de Almeida, nascida em 12 de julho 1875 e batizada em 14 de janeiro de 1876; e Anna de Almeida, nascida em 28 de maio de 1876 e batizada em 10 de fevereiro de 1877. Conforme nota do falecimento de d. Guilhermina, publicada no periódico Gutenberg, de 21 de janeiro de 1896, outro filho do casal era Benedicto Honorato de Almeida.

\footnotetext{
${ }^{6}$ Carta enviada por Justiniano Honorato d'Almeida para o conselheiro João Alfredo Correia de Oliveira. Disponível em: http://repositorio.ufpe.br/handle/123456789/14888. Acessado em: 07/08/2017. (Grifos nossos).

${ }^{7}$ A respeito dessa e de outras associações de caixeiros de Maceió, consultar: MACIEL, Osvaldo Batista Acioly. A perseverança dos caixeiros: o mutualismo dos trabalhadores do comércio em Maceió (1879- 1917). Tese (Doutorado em História) - Universidade Federal de Pernambuco, CFCH. Programa de Pós-graduação em História, 2011.
} 
Dentre os filhos de Justiniano e Guilhermina, João Luiz Honorato de Almeida foi sócio e aluno da Sociedade Instrução e Amparo dos Caixeiros de Maceió. Conforme Maciel (2011, p. 72), o estatuto da Sociedade definia cinco categorias de empregados auxiliares do comércio "[...] sendo a primeira dos corretores; em seguida vinha a dos leiloeiros; a terceira categoria dos agentes auxiliares do comércio seria a dos feitores, guarda-livros e caixeiros; a quarta seria composta dos trapicheiros e administradores de armazéns e depósitos; por fim, a quinta classe seria a dos condutores de gêneros e comissários de transportes".

João Luiz Honorato de Almeida frequentou as aulas noturnas de Português e de Escrituração Mercantil ministradas pela Sociedade Instrução e Amparo dos Caixeiros de Maceió, em 1883. A respeito do aproveitamento do aluno, Maciel (2010, p. 11, aspas no original) ressalta que

[...]. É bom notar, de qualquer modo, que nas avaliações que este aluno realiza, suas notas são ora boas, ora sofríveis, havendo uma oscilação na qualidade da aprendizagem. De todo modo, na ata de 20 de maio de 1883, informa-se que "por seu adiantamento", ou seja, pela assiduidade nas aulas e aprendizagem, frequentaria a partir de agora "a cadeira superior" de Português. Além de denotar o bom aproveitamento que o aluno vem obtendo na disciplina, deixa-se claro então que as aulas são ministradas pelo método individualizado. Esta constatação é natural, inclusive pelo baixo número de matriculados nas disciplinas [...].

João Luiz foi ainda Conselheiro Fiscal da Companhia Progressiva de Fiação e Tecido (GUTENBERG, 1892) e Tenente da $7^{\circ}$ Companhia do Primeiro Batalhão de Infantaria das Freguesias de Maceió e Jaraguá (ALMANAK DA PROVINCIA DAS ALAGOAS, 1891).

Justiniano, por sua vez, foi aposentado no cargo de Segundo Escriturário do Tribunal de Contas, conforme título declaratório publicado no Diário Oficial da União, datado de 26 de setembro de $1895^{8}$.

O fato de não ter exercido cargos de chefia, tendo iniciado a carreira como guarda simples, reforça a nossa hipótese de que se tratava de um aluno pobre. Outras suposições também podem ser aventadas, como por exemplo, a de que poderia ser filho de pais ricos ou mesmo ter sido criado por uma família afortunada. Entretanto, as fontes não nos permitem conclusões definitivas acerca da sua trajetória.

Nossa suposição baseia-se, ainda, na situação das crianças em estado de orfandade no século XIX, as quais, grosso modo, eram cuidadas por entidades religiosas, que ofereciam amparo a meninos e meninas desvalidas, de má sorte e má fortuna, ainda que outras tenham sido órfãos de pais afortunados. Muitas vezes tratava-se de filhos ilegítimos, aos olhos da sociedade cristã, e eram depositados na "roda dos enjeitados" para os cuidados de uma casa de caridade. Posteriormente, foram criadas instituições estatais, sobretudo, de aprendizes e artífices, para corrigir e controlar essa infância desafortunada. De acordo com Santos (2011, p. 81), esses estabelecimentos foram criados com a finalidade de "[...] retirar do espaço social urbanizado a infância pobre e desamparada, no intuito de civilizar, disciplinar e moldar comportamentos de uma classe classificada como 'perigosa' $[. .$.$] ".$

${ }^{8}$ ESTADOS UNIDOS DO BRAZIL. Diario Official, Directoria da Contabilidade do Thesouro, Capital Federal, 26set. 1895. Seção 1, p. 12. 
Mesmo não tendo prosseguido os estudos numa faculdade, como é possível conjecturar, Justiniano tão logo terminou suas aulas de Latim conseguiu galgar carreira na administração estatal, mas não nos cargos de chefia, cujos lugares eram reservados aos bacharéis. O fato dele mencionar, em 1888, que tinha cerca de 40 anos de serviço prestado corrobora com nossa afirmativa de ser uma criança pobre, pois isso indica que iniciou a vida profissional, por volta de 1848, ou seja, com 16 anos de idade. Ainda assim, não seguiu para uma faculdade, destino dos mais abastados. Fica, pois, evidente que, para Justiniano, era imprescindível à vida o trabalho, pois não possuía uma situação econômica confortável. Outro fato, já anunciado, diz respeito a seu filho primogênito ter estudado em horário noturno, numa instituição destinada a pessoas pobres, como a Sociedade Instrução e Amparo dos Caixeiros de Maceió. Por fim, consideramos importante lembrar que a frequência de Almeida nas aulas de Latim, bem como o contato e a aprendizagem da cultura letrada gerou para ele e sua família possibilidades de ascensão social.

\section{Os alunos pretos e pardos das aulas de Gramática Latina das Vilas de Atalaia e Penedo}

O mapa escolar datado de 15 de dezembro de 1847, do professor de Gramática Latina da Vila de Atalaia, Leopoldino Antonio Fonseca ${ }^{9}$, apresenta 27 alunos com idades entre 12 e 18 anos. As lições dadas na aula eram: nominativos, linguagens, sintaxe, Eutropio, Cornelio e Fábulas de Phedro, Salustio e Virgílio ${ }^{10}$.

Dentre os alunos da aula, Fonseca atesta que um era de qualidade parda, Joaquim Manoel da Costa. Com 18 anos e sendo natural de Atalaia, Costa é dado como filho do Reverendo Manoel Joaquim da Costa. Seu adiantamento era as lições de Salustio e Virgílio. Em mapa da mesma aula, porém do ano de $1844^{11}$, quando a cadeira era regida pelo professor padre João da Silva Cardozo, Costa, então com 16 anos aparece como filho de Antonia Maria de Jesus e teve como adiantamento nominativos. Vale salientar que o mapa de 1844 não apresenta a qualidade dos alunos, por isso não é possível fazer uma comparação nessa orientação.

Como é possível observar, comparando os dois mapas, o aluno Joaquim Manoel da Costa avançou em três anos na aula de Gramática Latina de nominativos para o estudo de Salustio e Virgílio. Outra questão importante diz respeito a sua filiação, sobretudo, a paternidade. Pois, ainda mesmo havendo a possibilidade real de que Joaquim Manoel fosse filho do padre Manoel Joaquim, este aparece também como pai de quatro crianças pardas no mapa das aulas primárias em Atalaia do ano de 1845 a 1847, conforme apresentou Santos (2011). Assim, a paternidade aqui pode não ser biológica, mas espiritual ou de apadrinhamento. Contanto, vale ressaltar que, no período, antes da chamada romanização ${ }^{12}$, é comum encontrar padres casados e/ou que constituíram famílias, em contraposição ao celibato.

\footnotetext{
9 Além de professor público foi Deputado Provincial na legislatura 1858-59 (Almanak da Provincia das Alagoas para o anno de 1873).

${ }^{10}$ Arquivo Público de Alagoas. Mapas escolares, 1847. Cx. 0061.

${ }^{11}$ Mappa dos Alumnos da Aula de Latinidade da Vila de Atalaia. In: Arquivo Público de Alagoas. Mapas escolares, 1844. Cx. 0061.

${ }^{12} \mathrm{O}$ conceito de romanização do catolicismo brasileiro nasceu no período posterior ao citado. A origem desse termo remete ao ambiente da chamada "questão religiosa" (1872-1875) e das tensões entre o Estado e a Igreja. Esta movimentou-se no sentido de aumentar o controle do papado sobre a Igreja Católica no Brasil, uma vez que pela lei do padroado os padres e bispos eram considerados funcionários do Estado, haja vista que eram
} 
O indício da qualidade parda, mesmo considerando a complexidade da terminologia na época, ajudou-nos a pensar, num universo escravocrata, a posição social que o indivíduo poderia assumir. Ao estudar as "dinâmicas de mestiçagens", Paiva (2015) mapeou termos e expressões empregadas no mundo ibero-americano, entre os séculos XVI e XVIII. Segundo o autor, a classificação dos sujeitos era dada por uma fórmula básica: nome + qualidade + condição. A condição estaria associada à questão jurídica: escravo, forro ou livre; a qualidade, por seu turno, tinha uma semântica complexa, pois poderia identificar os tipos humanos, como índio, crioulo, mameluco, mestiço, preto, pardo e mulato, bem como outras categorizações sociais: nação, raça, casta. Assim, para Paiva (2015), qualidade é diferente de cor, haja vista que a primeira servia para identificar, distinguir, hierarquizar, classificar e qualificar os indivíduos socialmente.

Raminelli (2012), salienta que a qualidade de um indivíduo estava relacionada com a sua nobreza ou dignidade. No entanto, havia um estreito vínculo entre a cor de pele e a qualidade de uma pessoa, assim na hierarquia das cores de pele, pretos e pardos, inatamente, de acordo com a visão da época, padeciam da falta de qualidade e eram incapazes de herdar a moral e o comportamento dos chamados brancos. Desta feita, conclui o autor que a qualidade era mais importante que a origem cativa.

O mapa manuscrito pelo professor padre Antonio Craveiro de Barros Leite da aula de Gramática Latina da vila de Penedo, datado de dezembro de 1847, apresenta um total de 40 alunos matriculados, com idade entre 12 e 25 anos. Dentre eles, sete alunos são declarados de qualidade preta ou parda. Eram eles: Manoel Simplicio do Sacramento, Jacyntho José Bizerra, Joaquim José dos Sanctos, Jose Vieira Sampayo, Jorge Martiniano Lopes, Manoel Antonio Tavares e Benvenuto Antonio de Caldas Lima ${ }^{13}$.

O primeiro aluno de qualidade preta é Manoel Simplício do Sacramento, à época com de 21 anos de idade. Natural de Penedo e filho de Athanario José do Rosario, Sacramento ingressou na aula em fevereiro de 1844 e em três anos seu adiantamento foi considerado provecto em Latim. Em mapa de ano anterior, o professor tinha considerado seu desenvolvimento como adiantado.

Após conclusão da aula, Sacramento seguiu a carreira eclesiástica. Em uma nota de gratidão ao médico da região do Baixo São Francisco, Dr. Socrates Guimarães, no Jornal do Penedo, de 5 de setembro de 1879, aparece o nome do padre Manoel Simplício do Sacramento (JORNAL DO PENEDO, 1879, $\mathrm{n}^{\circ}$ 35). Além do periódico, um documento publicado pela Diocese de Petrolina, no ano de 2010, denominado Os padres do interior: listas dos padres que serviram nas paróquias do alto sertão de Pernambuco (século XVII ao século XXI), o nome de Sacramento aparece como Vigário Encomendado da "freguesia de Santa Ana do Saco", em Parnamirim, quando fez um batizado de uma criança da freguesia de Salgueiro, em 1872, e assinou livro de óbitos de escravos, entre 1872 e 1876. O cônego Manoel Simplício do Sacramento foi também Vigário Cumulativo da Paróquia de Santo Antônio, em Salgueiro, nos idos de 1873 e de 1898 (CAVALCANTE, 2010). Ao mostrar que não apenas as motivações econômicas guiavam as relações escravistas, Maupeou (2008) assegura que o sacerdote deu liberdade à sua escrava, Joana, parda, de 28 anos, em virtude da

remunerados pelos cofres públicos. Dentre outras questões, a romanização visava sobretudo formar e disciplinar o clero. A respeito destas questões conferir Caes (2002).

${ }^{13}$ Arquivo Público de Alagoas. Mapas escolares, 1847, Cx. 0061. 
caridade e dos bons serviços prestados por ela. Ao alforriar a escravizada afirma o sacerdote que: "[...] concede-lhe a liberdade para que gose de hoje e para todo sempre como se nascida fôsse de ventre livre a que fais por caridade e sem remuneração alguma, e em atenção aos bons serviços que lhe tem prestado [...]." (LIVRO DE NOTAS DE TABELIÂO DE TACARATU, 1880 apud MAUPEOU, 2008, p. 81).

Outro aluno de qualidade parda é Jose Vieira Sampayo. Com 19 anos de idade, era filho de Manoel Vieira Sampayo, natural de Palmeira dos Índios e foi considerado pelo padre Antonio Leite como sendo hábil, aplicado e adiantado em Gramática Latina. Sampayo aparece ainda como aprovado simplesmente em Gramática Latina, conforme demonstra o mapa dos exames realizados no Liceu Alagoano, datado de 25 de novembro de $1859^{14}$. Em comunicado ao vice-diretor da instrução pública, datado de 1861, Sampayo pede autorização para criar cadeiras de primeiras letras, Latim e Francês na Vila das Palmeiras (atual município Palmeira dos Índios) ou em qualquer cidade da Província (DIARIO DAS ALAGOAS, 1861, [número não identificado]). Por ordens de pagamentos dos ordenados aos professores de instrução primária e dos vencimentos dos professores públicos, de 1863, foi possível identificar que Sampayo e sua esposa, Capitulina Clotilde Alves Vieira, eram professores primários da Vila de Palmeira dos Índios (DIARIO DAS ALAGOAS, 1863, n 148).

Jose Vieira Sampayo, que também foi tabelião, e Capitulina Clotilde Alves Vieira tiveram pelo menos duas filhas: Maria Lúcia Duarte (1863-?) e Anna Vieira Sampaio (1870-?). Segundo o periódico $O$ Caixeiro, Maria Lúcia fez seus estudos com os professores padre Procópio, Inácio Costa e Antonio Romariz e foi aprovada com distinção nos exames de Português e Francês, no ano de 1880 (O CAIXEIRO, 1880, n 19). Após a morte de seu marido, o poeta alagoano Antonio de Almeida Romariz, Maria Lúcia estabeleceu e dirigiu o Colégio Atheneu Alagoano para educação de meninas, no ano de 1883. Jornalista, fundou e foi redatora de A Revista Alagoana (1887), dedicada ao sexo feminino, como também do Almanaque Literário Alagoano das Senhoras (1889). Anna Vieira, por seu turno, matriculou-se no Liceu Alagoano, em 1882, e após concluir os preparatórios, em 1888, cursou a Faculdade de Direito, em Recife, sendo a primeira alagoana a obter o título de bacharel em Direito, no ano de 1893 (O ORBE, 1883, n 80; BARROS, 2005; ROSA E SILVA e BONFIM, 2007).

Quanto aos demais alunos de qualidade preta e/ou parda localizados no mapa do padre Antonio Leite não foi possível, até então, encontrar rastros da sua ação na sociedade alagoana e brasileira. O pouco que se sabe deles é o que consta no documento.

\footnotetext{
${ }^{14}$ Arquivo Público de Alagoas. Mapa de exames do Liceu da Capital, 1859. Cx.0061.
} 
Quadro 1 - Mapa da aula de Gramática Latina de Penedo de $1847^{15}$

\begin{tabular}{|c|c|c|c|c|c|c|c|c|c|}
\hline $\mathrm{N}^{\mathrm{o}}$. & Nomes & Filiações & Idades & Naturalidades & Entradas & $\begin{array}{l}\text { Qualidad } \\
\text { es }\end{array}$ & Habilidades & Applicações & Adiantamentos \\
\hline 1 & Joaquim Paulo Barboza & $\begin{array}{l}\text { Gabriel Antonio de } \\
\text { Carvalho }\end{array}$ & 25 & Penêdo & $\begin{array}{l}\text { Fevereiro } \\
1843\end{array}$ & Branco & Pouco habil & Applica-se & Provecto \\
\hline 2 & Joao Francisco de Godois & José Ferreira dos Sanctos & 19 & Penêdo & $\begin{array}{l}\text { Fevereiro } \\
1843\end{array}$ & Branco & P.h. & $\begin{array}{l}\text { Applica-se } \\
\text { pouco }\end{array}$ & Provecto \\
\hline 3 & Joaquim da Natividade Reis & Joaquim da Natividade Reis & 17 & Penêdo & $\begin{array}{l}\text { Fevereiro } \\
1844\end{array}$ & Branco & P.h. & $\begin{array}{l}\text { Applica-se } \\
\text { pouco }\end{array}$ & Provecto \\
\hline 4 & $\begin{array}{l}\text { Manoel Simplicio do } \\
\text { Sacramento }\end{array}$ & Athanario José do Rosario & 21 & Penêdo & $\begin{array}{l}\text { Fevereiro } \\
1844\end{array}$ & Prêto & P.h. & $\begin{array}{l}\text { Applica-se } \\
\text { pouco }\end{array}$ & Provecto \\
\hline 5 & Jacyntho José Bizerra & Felis José de Sancta Anna & 15 & Traipú & $\begin{array}{l}\text { Fevereiro } \\
1845 \\
\end{array}$ & Pardo & Habil & $\begin{array}{l}\text { Applica-se } \\
\text { pouco }\end{array}$ & Adiantado \\
\hline 6 & Joaquim José dos Sanctos & Agostinho José de Jesus & 16 & Penêdo & $\begin{array}{l}\text { Setembro } \\
1842\end{array}$ & Pardo & Inhabil & $\begin{array}{l}\text { Applica-se } \\
\text { pouco }\end{array}$ & Adiantado \\
\hline 9 & Jose Vieira Sampayo & Manoel Vieira Sampayo & 19 & Palmeira & $\begin{array}{l}\text { Março } \\
1846 \\
\end{array}$ & Pardo & $\mathrm{H}$. & Applica-se & Adiantado \\
\hline 20 & Jorge Martiniano Lopes & Joáo da Rosa Lopes & 20 & Penêdo & $\begin{array}{l}\text { Dezembro } \\
1846\end{array}$ & Pardo & P.h. & Applica-se & $\begin{array}{l}\text { Pouco } \\
\text { Adiantado }\end{array}$ \\
\hline 30 & Manoel Antonio Tavares & Antonio Diogo Tavares & 14 & Traipú & $\begin{array}{l}\text { Fevereiro } \\
1847\end{array}$ & Pardo & H. & $\begin{array}{l}\text { Applica-se } \\
\text { pouco }\end{array}$ & Arte \\
\hline 32 & $\begin{array}{l}\text { Benvenuto Antonio de } \\
\text { Caldas Lima }\end{array}$ & $\begin{array}{l}\text { José Antonio de Caldas } \\
\text { Mundahú }\end{array}$ & 15 & Capacaça & $\begin{array}{l}\text { Fevereiro } \\
1847\end{array}$ & Pardo & P.h. & $\begin{array}{l}\text { Applica-se } \\
\text { pouco }\end{array}$ & Arte \\
\hline 40 & $\begin{array}{l}\text { Rosidonio Augusto de } \\
\text { Carvalho Mora }\end{array}$ & $\begin{array}{l}\text { José Hygino de Carvalho } \\
\text { Mora }\end{array}$ & 10 & Penêdo & $\begin{array}{l}\text { Junho } \\
1847 \\
\end{array}$ & B & H. & $\begin{array}{l}\text { Applica-se } \\
\text { pouco }\end{array}$ & Arte \\
\hline
\end{tabular}

\section{TOTAL -40}

Sahiráo nestes três annos [...] maiores Estudos promptos em grammatica Manoel Simões de Mello, Lourenço Antonio de Andrade, José Marques de Sousa Barboza, Felippe Benicio de Resendes

Pinto, Luis José da Silva Lemos, José Joaquim de Almeida, e Laurindo da Boaventura.

Sahiráo [...] tratar de negocios adiantados Luis Antonio de Medeiros Lino, João Francisco de Sales, João Antonio das Chagas Craveiro, Nathaniel Fernandes de Araujo, Francisco de Assis

Asevedo Guimarães, Francisco Joaquim da Natividade Reis, e José Baptista Lemos. Este ultimo nada aproveitou.

Sahiráo para tratar de Agricultura Ignacio Xavier de Barros, José Aureliano Agra Barreto, João Baptista Ferreira, Joáo Ferreira.

Fonte: Arquivo Público de Alagoas. Mapas escolares, 1847, Cx. 0061.

\footnotetext{
${ }^{15}$ Apresentamos um quadro reduzido, dando ênfase aos alunos pretos e pardos.
} 
Assim, entramos num debate mais amplo, no qual uma vertente da historiografia vem travando, no sentido de redimensionar o estereótipo do negro na história imperial brasileira, via de regra, associado ao mundo da escravidão e da marginalização. No campo da historiografia da educação, semelhante entrave vem tentando desmistificar algumas afirmativas sobre a proibição de negros nas aulas públicas do Império, sobretudo, as aulas secundárias. $\mathrm{O}$ fato da legislação imperial proibir os escravizados de frequentarem as aulas públicas no Brasil acabou gerando alguns equívocos em relação à presença de negros nas cadeiras, pois algumas pesquisas da historiografia mais geral e, particularmente, da historiografia da educação aponta-os como sinônimo de escravizados, inclusive sem fazer ressalva ao aumento progressivo da população liberta, sobretudo, a partir da segunda metade do dezenove (VEIGA, 2008).

Outras afirmativas salientam que as experiências dos negros com o ensino secundário deram-se somente ao final do Império, especialmente após a década de 1870, ou na República. Ou mesmo ainda aqueles que asseguram a escolarização de negros no Império apenas em nível primário, notadamente os ingênuos libertos após 1871. Isso sem contar os que atestam que a população negra teve acesso à escolarização apenas em instituições de caridade ou recolhimento, como asilos e abrigos. A esse respeito, Fonseca $(2007$, p. 9) ressalta que

Há um padrão de tratamento em relação aos negros na historiografia educacional brasileira e sua principal característica é a promoção da invisibilidade dos membros deste grupo racial. Isto se manifesta nos trabalhos de história da educação através da afirmação explicita ou velada de que, no Brasil, os negros não frequentaram escolas. Em geral, esta afirmação é dirigida para uma caracterização dos períodos em que vigorou a escravidão e tem como pressuposto básico a ideia de que neste sistema a relação entre negro e as escolas só poderia ser pensada em termos de uma exclusão, ou seja, o negro era o escravo, e como havia restrições legais para que os escravos frequentassem escolas, estas instituições foram interpretadas sem levar em conta a possibilidade de sua relação com a população negra.

Nesse sentido, os mapas que apresentamos autorizam-nos a problematizar uma representação bastante consolidada de que o aluno do ensino secundário pertencia a uma elite branca, o qual, ao apropriar-se dos valores europeus de civilização e progresso, seguiam seus estudos nas faculdades e assumiam os cargos político-administrativos no Império e nas províncias (VEIGA, 2007; GONDRA; SCHUELER, 2008). Consideramos importante a discussão dessas questões para não entrar em generalizações, nem homogeneizar as afirmativas.

Entretanto, a partir dessa constatação, outras questões passam a surgir, como, por exemplo, qual seria o conceito de elite? Esses alunos negros e pardos encontrados pertenciam às elites cultural, econômica e/ou política? Se não pertenciam, como conseguiram ocupar aqueles espaços? Seriam eles cativos? Estavam de alguma forma burlando a legislação imperial? Partindo da premissa de que eles eram pobres, havia algum tipo de auxílio para esses alunos? Seriam eles favorecidos por uma política de apadrinhamento? Enfim, são várias indagações que ainda não temos respostas.

Uma pista para essas questões pode ser dada por Cruz (2008) quando salienta que, muitas vezes, os professores incluíam negros/pardos as suas aulas e mapas, mesmo aqueles que eram cativos e proibidos de estudar pela legislação, passando-os por livres para receber um ordenado maior, uma vez que o salário do professor estava vinculado à quantidade alunos. No entanto, o fato de termos encontrado a presença deles na educação secundária alagoana, 
ainda na primeira metade do dezenove, é fator de relevância para os estudos no domínio da história da educação brasileira.

Contudo, independentemente das indagações feitas, é importante salientar que as experiências educacionais em nível secundário nas Alagoas foram vivenciadas também por alunos "de cor". Assim, eles estiveram presentes nas aulas avulsas juntamente com os brancos, e entraram em contato com um tipo de educação oferecido às elites, ou seja, apropriaram-se de várias habilidades que os possibilitariam a galgar uma faculdade e, posteriormente, exercer funções públicas e cargos dirigentes.

\section{Considerações finais}

O presente texto analisou três mapas de aulas avulsas de Gramática Latina de Maceió, Atalaia e Penedo, que evidenciam a presença de um aluno órfão e oito alunos negros (pretos e pardos) na instrução secundária nas Alagoas, antes da metade do século XIX. A partir dos indícios fornecidos pelas fontes, buscamos rastrear a ação e atuação desses sujeitos negros e pobres na sociedade alagoano e para além dela.

É possível afirmar que a visão quase que fossilizada que pressupõe a ausência de alunos negros na educação secundária, no século XIX, não se confirma para a Província das Alagoas. Portanto, a presença de alunos pretos e pardos nas aulas avulsas de ensino secundário, em Alagoas, ainda que não seja acentuada, permite que os historiadores da educação enxerguem o perfil dos alunos daquela modalidade de ensino a partir de uma nova lente, que não aquela já solidificada nos trabalhos e pesquisas até então. Por outro lado, "[...] é importante lembrar que esses negros notáveis não expressavam as condições dos demais que viviam, em sua maioria sem escolarização, principalmente secundária e superior, daí a importância de revelá-los" (SANTOS, 2011).

Não se pode negar que a população negra teve um papel preponderante no desenvolvimento da Província, seja como escravizado, livre ou liberto trabalhando nas lavouras, nos serviços domésticos e no comércio (SANTOS, 2011), e como mostramos aqui, alguns frequentaram aulas e atuaram nos mais diversos espaços públicos da sociedade alagoana e brasileira.

É possível que tantos outros alunos negros frequentassem as aulas secundárias, uma vez que muitos mapas negligenciam o item cor ou qualidade, bem como este grupo tenha frequentado os mais diversos espaços e funções na sociedade brasileira. Por isso, consideramos fundamental a produção de pesquisas em história da educação que deem visibilidade à população negra/parda, para além do campo da escravidão e marginalização.

\section{Referências}

\section{Almanaques, Jornais, Mapas e Cartas}

ALMANAK da Província das Alagoas para o ano de 1873, $2^{\circ}$ ano, Maceió: Typographia Social de Amitas \& Soares, 1873.

ALMANAK do Estado das Alagoas para o ano de 1891, ano XX, Maceió: Typographia do Gutenberg, 1891.

ARQUIVO PÚBLICO DE ALAGOAS. Mapas escolares, 1844. Cx. 0061.

ARQUIVO PÚBLICO DE ALAGOAS. Mapas escolares, 1847, Cx. 0061. 
Carta enviada por Justiniano Honorato d'Almeida para o conselheiro João Alfredo Correia de Oliveira. Disponível em: http://repositorio.ufpe.br/handle/123456789/14888.

DIARIO DAS ALAGOAS, Maceió, [data não identificada] julho de 1861, ano IV, [número não identificado].

DIARIO DAS ALAGOAS, Maceió, 05 de julho de 1863, ano VI, n 148.

ESTADOS UNIDOS DO BRAZIL. Diario Official, Directoria da Contabilidade do Thesouro, Capital Federal, 26 set. 1895. Seção 1, p. 12.

GUTENBERG, Maceió, 19 de junho de 1892, ano XI, nº 134.

GUTENBERG, Maceió, de 21 de janeiro de 1896, ano XV, $\mathrm{n}^{\circ} 14$.

JORNAL DO PENEDO, Penedo, 5 de setembro de 1879, ano IX, nº 35.

O CAIXEIRO, Maceió, 29 de julho de 1880, ano I, nº 19.

O ORBE, Maceió, 15 de julho de 1883, ano V, nº 80.

Mappa resumido da população da Provincia das Alagoas. Disponível em: http://brazil.crl.edu/bsd/bsd/15/000038.html.

\section{Bibliográficas}

ARRIADA, Eduardo. A educação secundária na província de São Pedro do Rio Grande do Sul: a desoficialização do ensino público. PUCRS: Porto Alegre, 2007. Tese (Programa de Pós-Graduação em Educação) - Faculdade de Educação, Pontifícia Universidade Católica do Rio Grande do Sul, 2007.

BARROS, Francisco Reinaldo Amorim de. ABC das Alagoas: dicionário bibliográfico, histórico e geográfico de Alagoas. Vol. 62A. Brasília: Senado Federal, 2005.

CAES, Andre Luiz. As portas do inferno não prevalecerão: a espiritualidade católica como estratégia política (1872-1916). UNICAMP, Campinas, 2002 Tese (Programa de PósGraduação em História) - Instituto de Filosofia e Ciências Humanas, Universidade de Campinas, 2002.

CAVAlCANTE, Francisco José Pereira. Os padres do interior: listas dos padres que serviram nas paróquias do alto sertão de Pernambuco (século XVII ao século XXI). Petrolina, 2010. Disponível em: http://www.diocesedepetrolina.org.br/central/arquivos/file/ Os_Padres.pdf. Acesso em 23/02/2016.

CRUZ, Mariléia dos Santos. Escravos, forros, ingênuos em processos educacionais e civilizatória na sociedade escravista do Maranhão no século XIX. 2008. Tese (Doutorado em Educação) - Universidade Estadual Paulista Julio de Mesquita Filho, Araraquara, 2008.

CRUZ, Mariléia dos Santos. Políticas de ações negativas e aspirações de famílias negras pelo acesso à escolarização no Maranhão do século XIX. Revista Brasileira de História da Educação, Campinas: Autores Associados, n. 20, p. 73-104, 2009. 
FERRONATO, Cristiano de Jesus. Das aulas avulsas ao Lyceu Provincial: as primeiras configurações da instrução secundária na Província da Parahyba do Norte (1836-1884). UFPB: João Pessoa, 2012. Tese (Programa de Pós-Graduação em Educação) - Centro de Educação, Universidade Federal da Paraíba, 2012.

FONSECA, Marcus Vinícius. Pretos, pardos, crioulos e cabras nas escolas mineiras do século XIX. São Paulo: USP, 2007. p. 256. Tese (Doutorado em Educação) - Faculdade de Educação, Universidade de São Paulo, São Paulo, 2007.

GONDRA, José Gonçalves; SCHUELER, Alessandra. Educação, poder e sociedade no Império brasileiro. São Paulo: Cortez, 2008.

MACIEL, Osvaldo. Mutualismo, instrução e ideologia (Maceió, século XIX). In: V Encontro de Pesquisa em Educação em Alagoas, 2010. Anais do V Encontro de Pesquisa em Educação de Alagoas: Pesquisa em Educação: desenvolvimento, ética e responsabilidade social, Maceió, 2010.

MACIEL, Osvaldo. A perseverança dos caixeiros: o mutualismo dos trabalhadores do comércio em Maceió (1879 1917). Tese (Doutorado em História) - Universidade Federal de Pernambuco, CFCH. Programa de Pós-graduação em História, 2011.

MAUPEOU, Emanuele Carvalheira de. Cativeiro e cotidiano num ambiente rural: o Sertão do Médio São Francisco - Pernambuco (1840-1888). Recife, PE: UFPE. (Dissertação de Mestrado, 2008).

PAIVA, Eduardo França. Dar nome ao novo: uma história lexical da Ibero-Américaentre os séculos XVI e XVIII (as dinâmicas de mestiçagens e o mundo do trabalho). Belo Horizonte: Autêntica, 2015. 301 p.

RAMINELLI, Ronald. Impedimentos da cor. Mulatos no Brasil e em Portugal, c. 1640-1750. Varia História, Belo Horizonte, vol. 28, n. 48, p. 699-723, julho/dez. 2012. https://doi.org/10.1590/S0104-87752012000200011

ROSA E SILVA, Enaura Quixabeira; BONFIM, Edilma Acioli (orgs.). Dicionário das mulheres de Alagoas: ontem e hoje. Maceió: EDUFAL, 2007.

SANTOS, Mônica Luise. A escolarização de negros: particularidades históricas de Alagoas (1840-1890). Maceió, 2011. Dissertação (Programa de Pós-Graduação em Educação) Centro de Educação, Universidade Federal de Alagoas, 2011.

VEIGA, Cynthia Greive. Escola pública para os negros e os pobres no Brasil: uma invenção imperial. Revista Brasileira de Educação, v. 13, n. 39, set./dez. 2008, p. 502-516. https://doi.org/10.1590/S1413-24782008000300007 